nephron

Practice
Nephron 2018;138:1-12

DOI: $10.1159 / 000479074$
Received: February 11, 2017

Accepted after revision: June 26, 2017

Published online: September 2, 2017

\title{
Biomarkers of Renal Injury in Cirrhosis: Association with Acute Kidney Injury and Recovery after Liver Transplantation
}

\author{
Ashwani K. Singal ${ }^{a}$ Bradford Jackson ${ }^{i}$ Glauber B. Pereira ${ }^{b}$ Kirk B. Russ ${ }^{b}$ \\ Paul Stephen Fitzmorris ${ }^{b}$ Donny Kakati ${ }^{b}$ Page Axley $^{b}$ Sujan Ravi ${ }^{b}$ \\ Toni Seay ${ }^{c}$ Satish P. Ramachandra Rao ${ }^{f}$ Ravindra Mehta ${ }^{f}$ Yong-Fang Kuo ${ }^{g}$ \\ Karan P. Singh ${ }^{\text {h }}$ Anupam Agarwal ${ }^{\text {d-f }}$ \\ ${ }^{a}$ Division of Gastroenterology and Hepatology, Department of Medicine, ${ }^{b}$ Department of Medicine, \\ ${ }^{c}$ Clinical Research, Division of Gastroenterology and Hepatology, and d Division of Nephrology, \\ Department of Medicine, University of Alabama, and e Birmingham Veterans Administration Medical \\ Center, Birmingham, AL, ${ }^{f} \mathrm{O}$ 'Brien Center for AKI Research Biomarker Laboratory, Division of Nephrology, \\ Department of Medicine, University of California, San Diego, CA, ${ }^{9}$ Department of Biostatistics, University of Texas \\ Medical Branch, Galveston, TX, h'Department of Epidemiology and Biostatistics, School of Community and Rural \\ Health, University of Texas Health Science Center, San Antonio, TX, and 'Center for Outcomes Research, JPS Health \\ Network, Fort Worth, TX, USA
}

\section{Keywords}

Simultaneous liver kidney · Acute kidney injury •

Biomarkers · Cirrhosis · End-stage renal disease

\begin{abstract}
Background: To define urine or serum biomarkers in predicting renal function recovery after liver transplantation (LT). Methods: Adults listed for LT (February 2011-July 2014) and with modified diet for renal disease-6 (MDRD-6) $<60 \mathrm{~mL} / \mathrm{min}$ provided urine/blood samples at baseline and serially until LT for biomarkers in serum $(\mathrm{pg} / \mathrm{mL})$ and urine (pg/mg creatinine). Results: Of 271 LT listed patients (mean age 57 years, 63\% males, median listing MELD 17.5), 1 year acute kidney injury (AKI) probability was $49 \%$, with odds of
\end{abstract}

() 2017 S. Karger AG, Basel

E-Mail karger@karger.com www.karger.com/nef
1.3-, 3.0-, 4.6-, and 8.5-fold times for listing MELD 16-20, $21-$ $25,26-30$, and $>30$, compared to MELD $<16$. Thirty-seven people died over 1 year from the time of listing, with twofold increased odds with AKI. Among 67 patients with MDRD $<60$, only urinary epidermal growth factor was different comparing $A K I$ (increase in serum creatinine $\geq 0.3 \mathrm{mg} / \mathrm{dL}$ from baseline within past 3 months) vs. no AKI (2,254 vs. 4,253, $p=$ 0.003). Differences between acute tubular necrosis (ATN) and hepatorenal syndrome could not be ascertained for a small sample of 3 patients with ATN. Analyzing 15 of 43 receiving LT and MDRD- $6<30$ prior to $L T$, biomarkers were not different comparing 5 patients recovering renal function (MDRD- $6>50 \mathrm{~mL} / \mathrm{min}$ ) at 6 months vs. 10 without recovery. Conclusions: AKI is common among LT listed patients, with a negative impact on transplant-free survival. Serum and 
urine biomarkers are not associated with the recovery of renal function after LT. Multicenter studies are suggested to (a) develop strategies to reduce the development of AKI and (b) derive novel biomarkers for use in accurately predicting renal recovery after $\mathrm{LT}$.

(C) 2017 S. Karger AG, Basel

\section{Introduction}

Acute kidney injury (AKI) occurs commonly in patients with cirrhosis and its prevalence rates are in the range $19-49 \%$ [1-8]. It negatively impacts patient survival before and after liver transplantation (LT) $[1,5,6$, 9-12]. AKI in patients with cirrhosis occurs invariably due to volume loss; hepatorenal syndrome (HRS) due to vasoconstriction and reduced renal blood flow; and acute tubular necrosis (ATN) due to prolonged pre-renal factors, sepsis, or nephrotoxic insults $[8,11,13-15]$. To our knowledge, there are no studies describing AKI among patients with cirrhosis after they are listed for LT.

Routine clinical and laboratory evaluation is often unable to accurately differentiate HRS from intra-renal causes, and renal biopsy is invasive with a potential for complications $[7,8,16]$. AKI secondary to ATN may often require simultaneous liver kidney (SLK) transplantation for renal function recovery. In contrast, patients with AKI due to HRS usually recover after LT alone. Imperfect criteria for allocating SLK transplantation in the setting of AKI [17, 18], combined with the introduction of MELD score for LT listing [19], have resulted in over $300 \%$ increase in SLK transplantation [18, 20]. Given the scarcity of donor kidneys [21], there is a need for biomarkers or models for accurate prediction of renal recovery after LT alone for the optimal allocation of donor kidneys.

Biomarkers of renal injury such as neutrophil gelatinase-associated lipocalin (NGAL), kidney injury molecule-1, interleukin-18 (IL-18), human endothelin-1 (HE1), uromodulin (UMOD), epidermal growth factor (EGF), fatty acid-binding protein, and many others have been shown to predict recovery of renal function in patients with AKI without liver disease, development of AKI during LT, and differentiating HRS from ATN [10, 22, 23]. However, there are limited data on efficacy of these biomarkers in predicting recovery of renal function after LT alone. We prospectively recruited patients with liver cirrhosis listed for LT with specific aims to examine the (a) probability of the development of AKI and its impact on waitlist mortality and the (b) association of levels of serum and urine biomarkers of renal injury with the type of AKI before LT and with renal function recovery after LT.

\section{Methods}

\section{Study Population}

This is a prospective-retrospective cohort study of adult patients with liver cirrhosis listed for LT between February 2011 and July 2014 (Fig. 1). Patients with prior liver or kidney transplant were excluded. The prospective cohort included cirrhosis patients listed for LT between April 2013 and July 2014, and were recruited after they gave their informed consent to be part of an ongoing prospective longitudinal study to define urine and serum biomarkers in predicting recovery of renal function after LT. The retrospective cohort included patients listed between February 2011 and the recruitment of prospective study cohort starting April 2013. Both cohorts were followed until the data cut-off date of December 2015. Medical charts were reviewed to obtain prospective follow-up data on the retrospective cohort. The study was approved by our institutional review board. The study was conducted in accordance to the Declaration of Helsinki. The clinical and research activities being reported are consistent with the Principles of the Declaration of Istanbul as outlined in the "Declaration of Istanbul on Organ Trafficking and Transplant Tourism."

\section{Study Outcomes}

One-year probability of AKI and of patient survival after LT listing was the expected study outcome.

Collection of Urine and Serum Samples

A subgroup of patients with modified diet for renal disease- 6 (MDRD-6) $<60 \mathrm{~mL} / \mathrm{min}$ of the prospective cohort agreed to provide $50 \mathrm{~mL}$ urine and $10 \mathrm{~mL}$ blood samples at the time of recruitment and then during every future encounter in the outpatient department or during inpatient admission, until LT is performed or they are removed from the waitlist. Patients receiving LT alone were followed up for 6 months to measure their renal function and assess the recovery of renal function. Patients receiving SLK transplantation were excluded from the analysis (Fig. 1). See online supplementary material methods section (for all online suppl. material, see www.karger.com/doi/10.1159/000479074) for details on data collection, definitions, measurement of serum and urine biomarkers, and statistical analyses approach.

\section{Results}

\section{Study Population}

A total of 271 patients (median age 56 years, 63\% males, $83 \%$ Caucasians, median MDRD-6 and MELD score at listing of $66 \mathrm{~mL} / \mathrm{min}$ and 18 , respectively) who fulfilled the eligibility criteria for the study were analyzed (Table 1). Preexistent CKD was present in 64 (24\%) patients, which was due to diabetes in 31 patients. 
Fig. 1. Study design and population. LT, liver transplant; AKI, acute kidney injury.

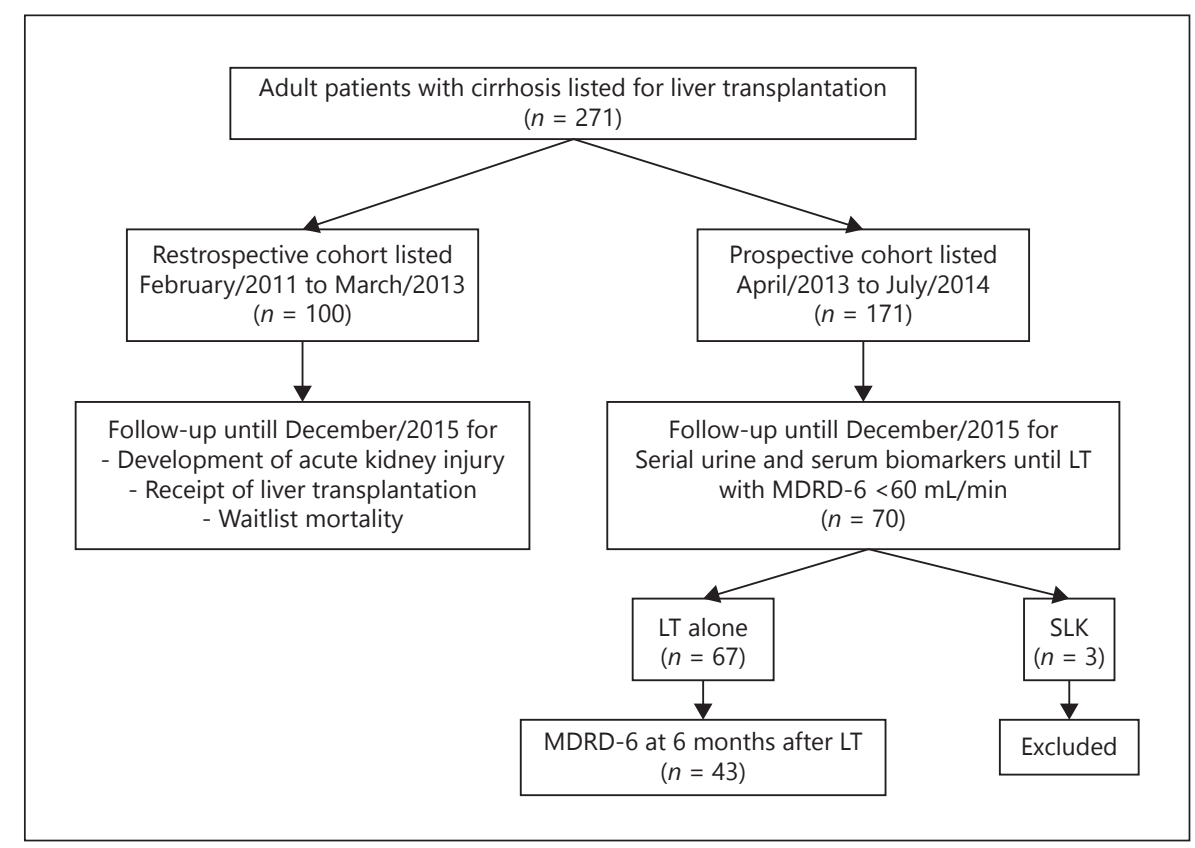

Table 1. Baseline characteristics at the time of listing for liver transplantation

\begin{tabular}{|c|c|c|c|c|}
\hline Variable & Total $(n=271)$ & No AKI $(n=164)$ & AKI $(n=107)$ & $p$ value \\
\hline Age, years, median (IQR) & $56(50-62)$ & $57(51-62)$ & $56(48-61)$ & 0.064 \\
\hline Males, $n(\%)$ & $170(63)$ & $106(65)$ & $64(60)$ & 0.42 \\
\hline Caucasian & $226(83)$ & $140(85)$ & $86(80)$ & \\
\hline African American & $33(12)$ & $15(10)$ & $17(16)$ & \\
\hline Hispanic & $6(2)$ & $2(1)$ & $4(4)$ & \\
\hline Liver disease etiology, $n(\%)$ & & & & 0.82 \\
\hline Hepatitis C & $100(37)$ & $62(38)$ & $38(35)$ & \\
\hline NASH & $72(27)$ & $40(24)$ & $32(30)$ & \\
\hline Alcohol & $36(13)$ & $23(14)$ & $13(12)$ & \\
\hline Other & $63(23)$ & $39(24)$ & $24(23)$ & \\
\hline Beta blockers & $143(53)$ & $88(54)$ & $55(51)$ & 0.72 \\
\hline Refractory & $95(36)$ & $47(29)$ & $48(45)$ & \\
\hline Hepatic encephalopathy & $168(62)$ & $91(56)$ & $77(72)$ & 0.008 \\
\hline Varices & $170(63)$ & $101(62)$ & $69(64)$ & 0.63 \\
\hline Preexisting HCC, $n(\%)$ & $56(21)$ & $41(25)$ & $15(14)$ & 0.029 \\
\hline Preexisting CKD, $n(\%)$ & $64(24)$ & $27(16)$ & $37(35)$ & 0.0006 \\
\hline Platelets, $\times 10^{9} / \mathrm{L}$, median (IQR) & $73(55-114)$ & $72(52-105)$ & $77(59-127)$ & 0.38 \\
\hline Serum sodium, mEq/L, median (IQR) & $136(134-139)$ & $137(134-139)$ & $135(132-138)$ & 0.01 \\
\hline Listing MELD score, median (IQR) & $18(14-22)$ & $17(14-19)$ & $19(15-25)$ & 0.0003 \\
\hline Listing MDRD-6, mL/min, median (IQR) & $66(49-91)$ & $76(57-101)$ & $56(37-73)$ & $<0.0001$ \\
\hline
\end{tabular}

AKI, acute kidney injury; IQR, interquartile range; NASH, non-alcoholic steatohepatitis; HCC, hepatocellular carcinoma; CKD, chronic kidney disease; MELD, model for end-stage liver disease; MDRD, modified diet in renal disease; HR, hazard ratio; CKD, chronic kidney disease; MELD, model for end-stage liver disease. 

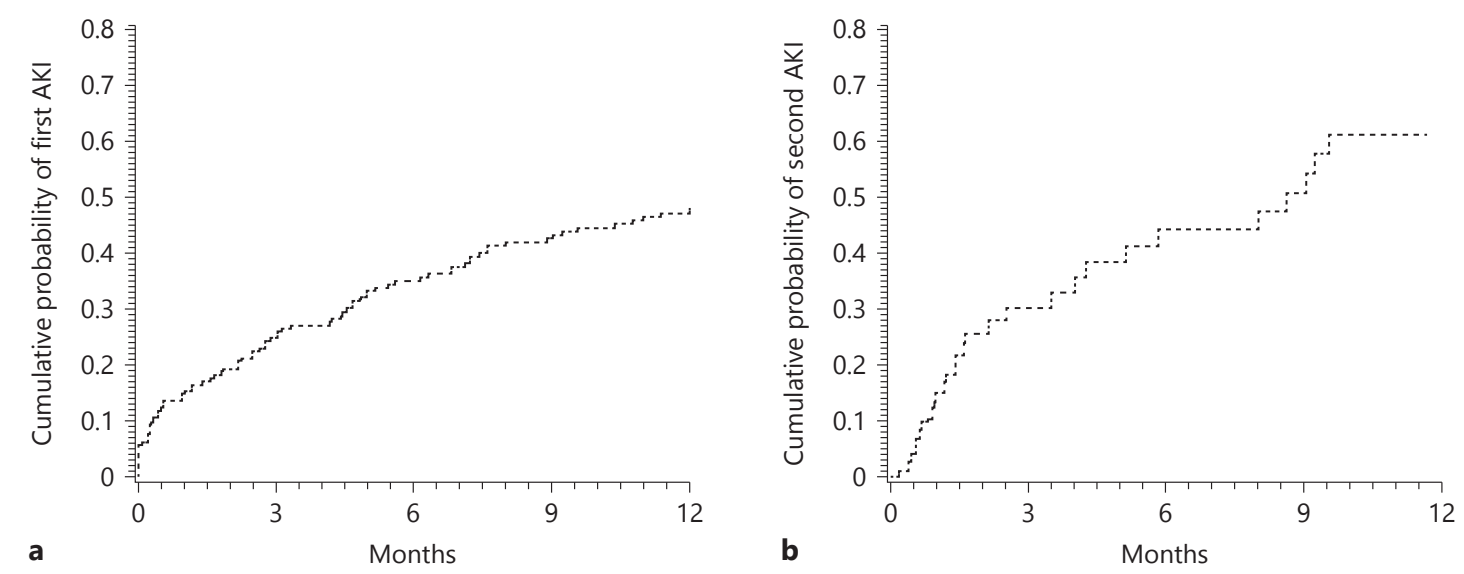

Fig. 2. a Cumulative probability of the development of acute kidney injury (AKI) at 1 year from the time listed for liver transplantation (LT). The results show that the cumulative probability over 1 year for the development of AKI is about 49\% from the time of listing for LT. b Cumulative probability of the development of a

Common causes of liver cirrhosis were hepatitis $\mathrm{C}$ virus infection, nonalcoholic steatohepatitis, and alcohol use in $100(37 \%), 72(27 \%)$, and $36(13 \%)$ patients respectively. Of 100 patients with HCV infection, 44 had received treatment for this disease. A total of 230 (85\%) patients had decompensated disease with either the presence of ascites or hepatic encephalopathy or varices (Table 1).

Of the prospective cohort, 70 patients (mean age 58 years, 54\% males, $84 \%$ Caucasians) with MDRD- $6<60$ (median $37 \mathrm{~mL} / \mathrm{min}$ ) were recruited to provide serum and urine samples for biomarkers measurements (online suppl. Fig. 1; online suppl. Table 1). About half of these patients had underlying CKD ( $10 \%$ on hemodialysis) due to associated comorbidities of diabetes mellitus in $49 \%$ and hypertension in $46 \%$ (Table 1). Of 7 patients on hemodialysis at the time of inclusion into the study, 3 were receiving this for end-stage renal disease (all these receiving SLK transplantation and were excluded from the analysis on biomarkers), and remaining 4 were initiated on dialysis for AKI.

A total of 242 samples were collected from 70 patients from the time of recruitment until removal from the transplant list, with 131 serum samples from 69 patients and 111 urine samples from 65 patients (online suppl. Fig. 1). A total of 35 and 37 patients provided only the baseline serum or urine sample, and 22 and 18 patients provided 2 serum or urine samples. The remaining pa-

tients provided more than 2 samples with maximum of 5 serum samples by each of the 2 patients and 6 urine samples by 1 patient (online suppl. Fig. 1).

\section{Probability of AKI}

Over a median (interquartile range) follow-up period of $1.43(0.85-2.17)$ years, 107 of 271 (39.5\%) patients developed the first episode of AKI, with 1 year probability of $49 \%$ (Fig. 2a). Similar probabilities at listing MELD score $<16(n=95), 16-20(n=100), 21-25(n=33), 26-30$ $(n=19)$, and $>30(n=24)$ were $31.9,42.8,73.7,72.8$, and $91.7 \%$ respectively (log rank $p<0.0001$; online suppl. Fig. 2). Of 107 first AKI episodes, volume responsive prerenal was the most common etiology of AKI in 61 (57\%) patients followed by ATN in 28 (27\%), HRS in 10 (9\%), and miscellaneous causes in 8 (7\%) patients including postrenal etiology in 2 patients (online suppl. Fig. 3). Patients with AKI $(n=107)$ compared to 164 patients without AKI were more likely to have preexisting $\mathrm{CKD}$, more likely to have refractory ascites and hepatic encephalopathy, less likely to have hepatocellular carcinoma, and had lower listing MDRD-6 and serum sodium, and higher MELD score (Table 1). The 2 groups were no different on decompensated disease ( 82 vs. $89 \%, p=0.15$ ) and on varices and platelet count (Table 1). The proportion of patients receiving treatment for $\mathrm{HCV}$ infection was also similar in the 2 groups at $44 \%$ (27 of 62 ) vs. $45 \%$ (17 of $38), p=0.91$. 
Fig. 3. Kaplan-Meier curve showing survival 1 year from the time of listing for liver transplantation: Comparison of patients with and without acute kidney injury (AKI). Overall survival was about $86 \%$, significantly lower among patients with AKI compared to those not developing AKI (72.2 vs. $83 \%, \log \operatorname{rank} p=0.025)$.

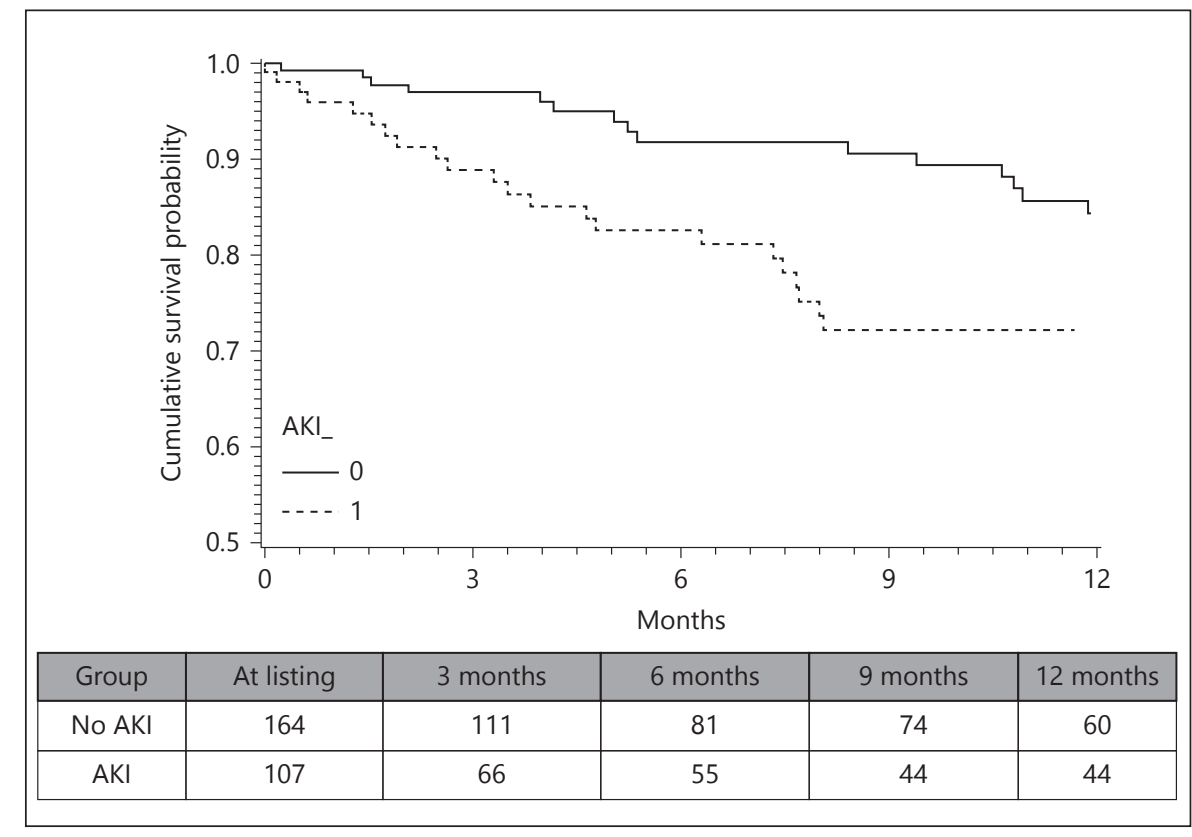

\section{Predictors of AKI}

On a cox proportional hazard regression analysis model, MELD score and serum sodium at listing independently predicted the development of AKI at 1 year, with 3 point increase in MELD score increasing the risk by $39 \%$ (online suppl. Table 2). The Cox regression model built with MELD score as a categorical variable showed AKI risk at 1 year from the time of listing to increase linearly by 335,399 , and $1,223 \%$, respectively, for listing MELD score of 21-25, 26-30, and >30, respectively, compared to MELD score $<15$ (online suppl. Table 2).

\section{Impact of AKI on Waitlist Mortality}

A total of 73 (27\%) patients died while waiting for LT, this number being higher among patients with AKI (33.6 vs. $12.2 \%, p=0.0001$ ). Of 73 deaths on the waitlist, 37 occurred within the first year from the time of listing (21 among patients with AKI). One year probability of survival from the time of listing for LT was about $86 \%$, lower in patients with AKI ( 72.2 vs. $83 \%, p=0.025$; Fig. 3). After controlling for demographics (age and gender), diabetes, obesity, and listing MELD score, development of AKI increased risk for waitlist mortality at 1 year from the time of listing by over twofold: HR (95\% CI) of 2.27 (1.28-4.02, $p=0.005$; online suppl. Table 3$)$. Within the group of 107 patients with AKI, cox proportion hazard regression analysis was built again. Recurrent AKI was not a predictor of waitlist mortality, 0.89

Biomarkers and Liver Transplantation
$(0.39-2.02, p=0.79)$. Significant predictors were MELD at listing $1.07(1.03-1.12, p=0.002)$ and obesity 1.82 $(1.09-3.01, p=0.02)$.

A total of 145 of 271 (54\%) patients were transplanted during the study period, with 8 (2.96\% of both the cohorts and $5.5 \%$ of all LT) receiving SLK. The proportion of patients receiving LT was similar to that of patients with and without AKI ( 49 vs. $53 \%, p=0.47$; online suppl. Fig. 4). MDRD-6 was consistently lower among patients with AKI at listing, and then at 3, 6, and 12 months from the time of listing, compared to patients without AKI However, patients surviving the AKI episode without LT return their MDRD-6 to baseline (median MDRD-6 around $60-65 \mathrm{~mL} / \mathrm{min}$; online suppl. Fig. 5).

\section{Recurrent AKI}

A total of 147 episodes of AKI developed in $107 \mathrm{pa}$ tients, 27 with 2 AKI episodes, 12 with 3 episodes, and 1 patient had more than 3 episodes (online suppl. Fig. 3 ). The etiology of recurrent AKI was similar to the proportion of etiologies in the first episode (online suppl. Fig. 3). Of 107 patients with the first AKI episode, the second AKI occurred in 26 (24\%) patients among LTfree survivors, with 1-year probability of $60 \%$ (Fig. 2b). Respective cumulative probabilities for the second episode of AKI were 25,30 , and $21 \%$ among patients with listing MELD $<21,21-25$, and $>25$ compared to MELD $<20$. 


\section{Biomarker Analysis}

a. $M D R D-6>30$ vs. $\leq 30 \mathrm{~mL} / \mathrm{min}$ : of 122 samples, 34 samples with MDRD- $6 \leq 30$ (median $23 \mathrm{~mL} / \mathrm{min}$ ) compared to 88 samples with MDRD- $6>30$ (median $51 \mathrm{~mL} / \mathrm{min}$ ) had significantly higher serum HE-1 and NGAL levels (online suppl. Table 4; Fig. 4a, b). On urine biomarkers analysis, EGF and IL-18 were significantly lower for samples with MDRD-6 $\leq 30$ (online suppl. Table 4; Fig. 4c, d). Other biomarkers were not significantly different comparing the 2 strata of MDRD-6 (online suppl. Table 4).

b. AKI vs. no AKI: of 134 samples, 37 samples with adjudication of AKI at the time of sample collection compared to 97 samples without AKI had significantly higher serum NGAL and a trend for higher HE-1 levels (Table 2; Fig. 4e, f). On urine biomarkers analysis, only EGF was significantly different with lower levels for samples with AKI (Table 2; Fig. 4g). Other biomarkers were not significantly different when the 2 strata of MDRD- 6 were compared (Table 2).

c. Type of AKI: of 37 samples with AKI, cause of AKI was pre-renal in 22, HRS in 12, and ATN in 3 patients. Compared to pre-renal AKI, serum NGAL was higher in ATN and serum HE-1 was higher in HRS (Table 3). However, statistical comparison could not be derived for comparing ATN and HRS with only 3 observations with AKI due to ATN (Table 3).

d. CKD vs. no CKD: of 134 samples, 62 samples from patients with CKD (median MDRD- 6 of $34 \mathrm{~mL} / \mathrm{min}$ ) differed only for urinary EGF, compared to samples obtained from patients without CKD (median MDRD-6 of $51 \mathrm{~mL} / \mathrm{min}$; online suppl. Table 5; Fig. 4b). Further, samples from CKD patients tended to have higher serum NGAL and urinary albumin (online suppl. Table 5; Fig. $4 \mathrm{a}, \mathrm{c})$.

e. Recovery of Renal Function after LT Alone: of 70 patients recruited into the study, 46 were transplanted until the end of the data collection period. Of these, 43 received liver alone (mean age 57 years, 53\% males, $84 \%$ Caucasians, baseline MDRD- 6 of $40 \mathrm{~mL} / \mathrm{min}$ ) and 3 patients received SLK transplantation (Table 1). About $44 \%$ of transplanted patients had underlying CKD, with pretransplant hemodialysis in 1 patient (Table 1). Of 43 patients receiving $\mathrm{LT}$ alone, 24 patients provided a sample

Fig. 4. Box whisker plots comparing samples with modified diet for renal disease-6 (MDRD-6) $>30 \mathrm{~mL} / \mathrm{min}$ vs. samples with MDRD- $6 \leq 30 \mathrm{~mL} / \mathrm{min}$ for (a) serum human endothelin-1 (HE-1; $\mathrm{pg} / \mathrm{mL}$; b) serum neutrophil gelatinase-associated lipocalin or NGAL (c) urinary endothelial growth factor (d) urinary interleu- within a month prior to LT, and these patients did not differ at baseline from all the transplanted patients (Table 1).

To examine the association of serum and urinary biomarkers with the recovery of renal function, we focused on 15 patients receiving liver alone with MDRD- $6<30$ at the last sample obtained within a month prior to LT (Table 4). Of these, 5 patients were able to recover their renal function and 10 patients did not recover their renal function, with recovery defined as return of MDRD- 6 to $>50$ at 6 months after LT. None of the biomarkers in serum and urine on the latest sample available prior to LT was different when patients with and without recovery of renal function were compared. There was a trend for higher UMOD among patients showing recovery of renal function compared to patients not recovering renal function at 6 months after LT (online suppl. Fig. 6a). Other details on pre-transplant variables and post-transplant use of calcineurin inhibitor are provided in online supplementary Table 5 .

\section{Discussion}

The frequency of AKI in patients with cirrhosis varied between 19 and $49 \%$, which is similar to that of the current study [1-6]. Differences across studies may be due to study population and follow-up time. In this study, the probability of occurrence of AKI at 1 year from the time of listing for LT was $49 \%$. In a retrospective study on 82 patients with Child's class C cirrhosis, AKI occurred in about $23 \%$ patients over a 1 -year period [24]. In another study, the incidence of AKI was $18 \%$ at 1 year among hospitalized patients with cirrhosis [25]. AKI in cirrhosis is most commonly due to volume-responsive prerenal injury followed by ATN and type $1 \mathrm{HRS}$, similar to what we found in the current study $[7,8,11,14,15]$.

Biomarkers such as NGAL, kidney injury molecule-1, IL-18, and FABBP-2 can diagnose AKI earlier, differentiate ATN from HRS, and predict outcomes [22, 23, 26$31]$. Of these, serum NGAL and urinary IL-18 were different in this study. Our study population with MDRD$6<60$ and the presence of underlying CKD probably kin (IL)-18; comparing samples without acute kidney injury (AKI) at the time of sample collection vs. samples with AKI for (e) serum HE-1 (f) serum neutrophil gelatinase-associated lipocalin or NGAL; comparing samples without chronic kidney disease (CKD) vs. samples with CKD for (g) urinary endothelial growth factor.

(For figure see next page.)
Singal et al. 

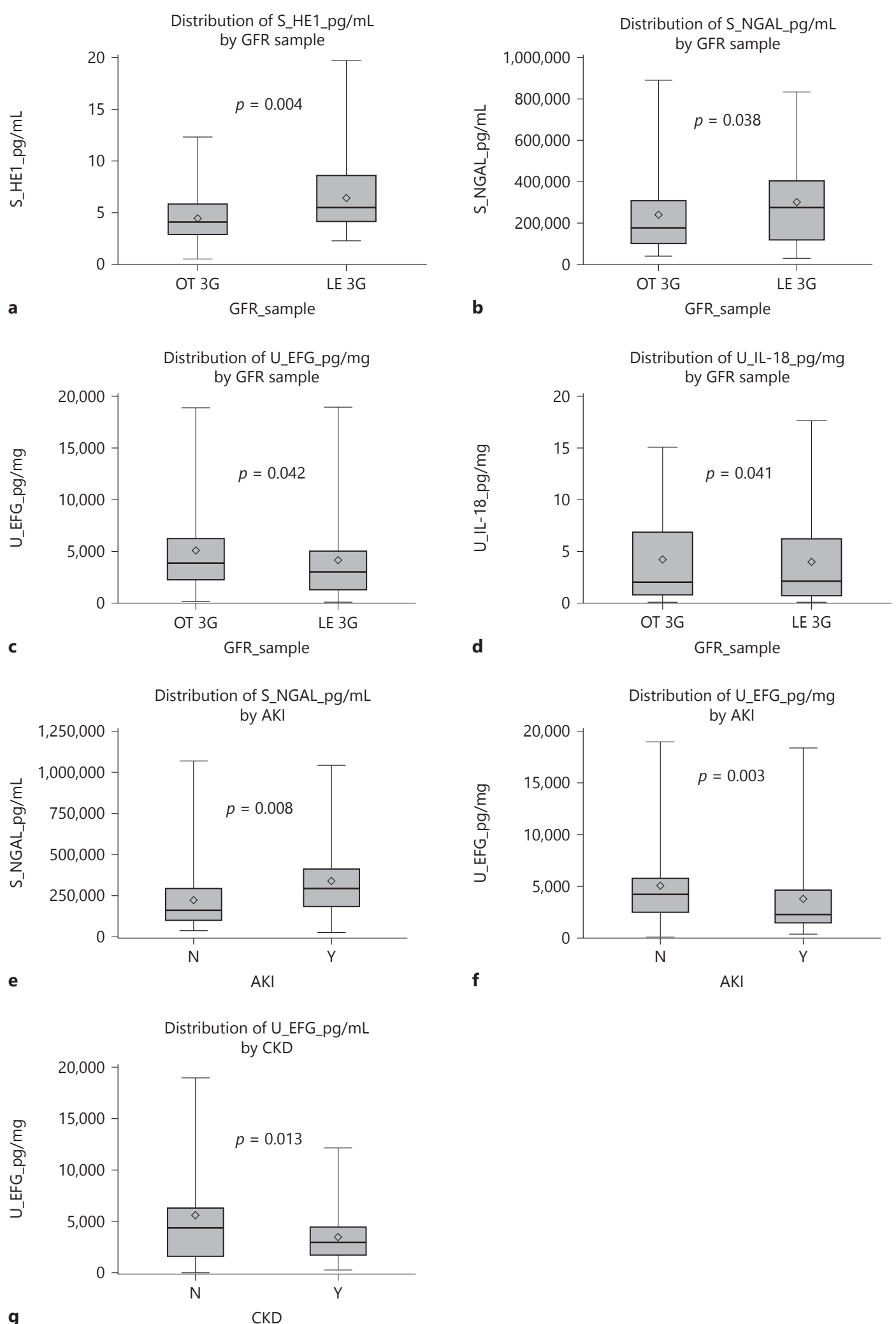
Table 2. Biomarkers levels in serum $(\mathrm{pg} / \mathrm{mL})$ and in urine $(\mathrm{pg} / \mathrm{mg}$ creatinine) comparing samples without vs. with AKI at the time of sample collection

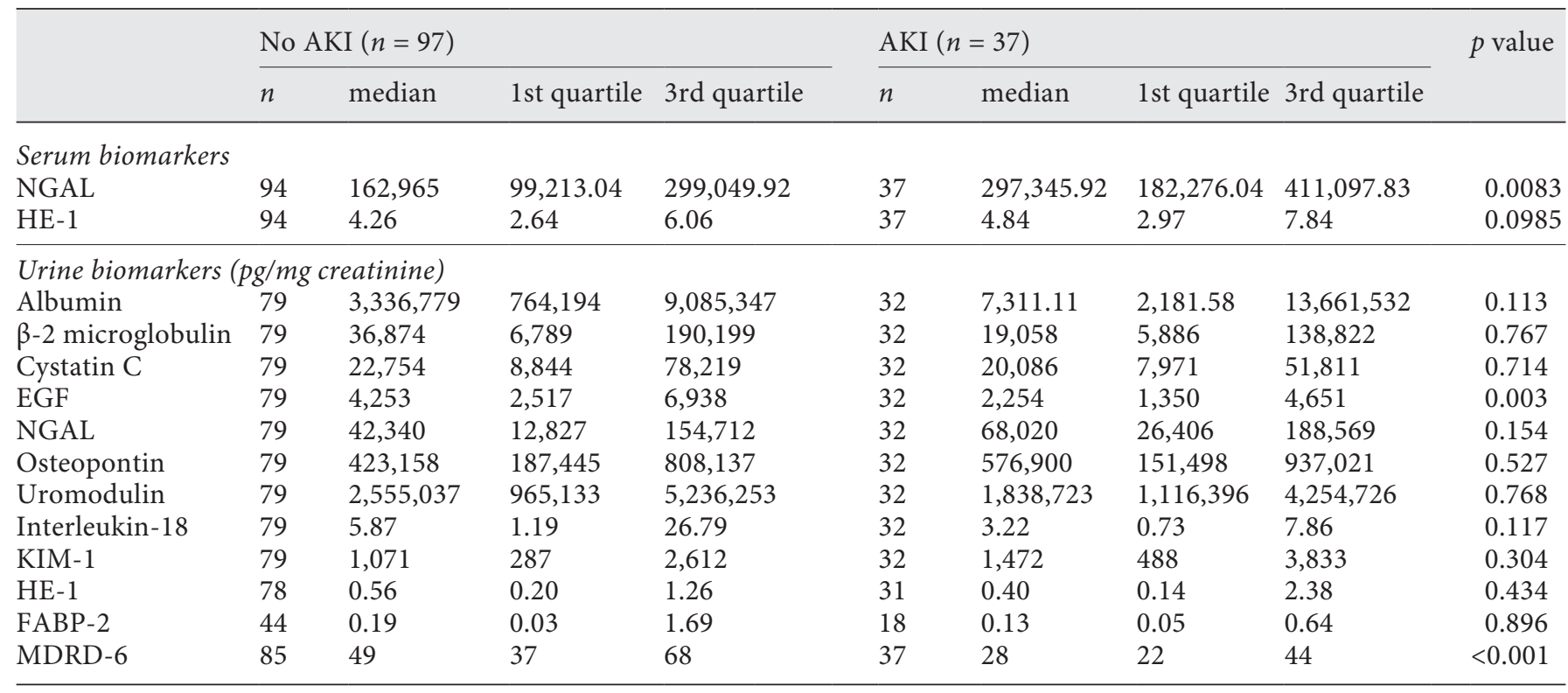

AKI, acute kidney injury; NGAL, neutrophil gelatinase-associated lipocalin; EGF, epidermal growth factor; KIM, kidney injury molecule; HE, human endothelin; FABP, fatty acid binding protein; MDRD, modified diet for renal disease.

explain our findings [23, 31-33]. Although, the levels were higher in ATN compared to HRS in this study, the small sample size limited the extent of statistical difference.

Few studies have previously shown the association of risk of the development of AKI with the Child Turcotte Pugh stage $[3,34]$. There is only one study showing the association of AKI occurrence with the baseline MELD score [6]. However, this prospective study examined for in hospital AKI, unlike our study examining 1-year probability of AKI among LT-listed patients. In another prospective study on 92 cirrhosis patients, 82 episodes of AKI occurred. Of 49 patients developing AKI in this study, 33 (67\%) developed a second episode of AKI [35], similar to our study. Studies have negative impact of AKI on the outcome of cirrhosis patients and on the need for hospitalization, intensive unit care, dialysis, and use of hospital resources, as observed in the current study [1, 5, 6, 9-12]. A small number of patients with documented use of statins in this study limited the analysis of the impact of these drugs on the survival. Of note, the use of beta blockers was not associated with the development of AKI risk in this study.

We also examined other biomarkers, such as HE-1, EGF, and UMOD, which have not been evaluated earlier in patients with cirrhosis or in terms of biomarkers such as cystatin $\mathrm{C}, \beta 2 \mathrm{M}, \mathrm{OPN}$, and albumin, data are scanty $[36,37]$. HE- 1 is a peptide released from endothelial cells resulting in renal vasoconstriction [38]. HE-1 increases in plasma and in urine in HRS patients [39]. In our study, serum and urinary HE-1 levels were the highest in HRS followed by ATN and levels were the lowest in pre-renal AKI, similar to earlier reports. Cystatin-C, a low molecular weight protein exclusively eliminated by glomerular filtration, has been used for GFR calculation [40]. In one study, plasma cystatin C levels predicted sustained AKI and its outcomes among patients in the intensive care setting [41]. In the current study, there were no differences on urinary cystatin-C levels based on AKI. $\beta 2 \mathrm{M}$ is a small molecule freely filtered by glomerulus and reabsorbed by proximal tubules, and its serum levels increase with a decline in GFR [42]. In this study, there were no differences on urinary $\beta 2 \mathrm{M}$ levels, as levels may be confounded with infections and inflammatory state [43]. OPN is an inflammatory cytokine, and its serum levels predict the onset of AKI and its outcome [44]. In the current study, OPN urinary levels were no different for AKI, likely due to confounding with underlying infections and the presence of CKD [45]. Albuminuria is well described as a marker for CKD and for diabetic nephropathy. In the current study, 

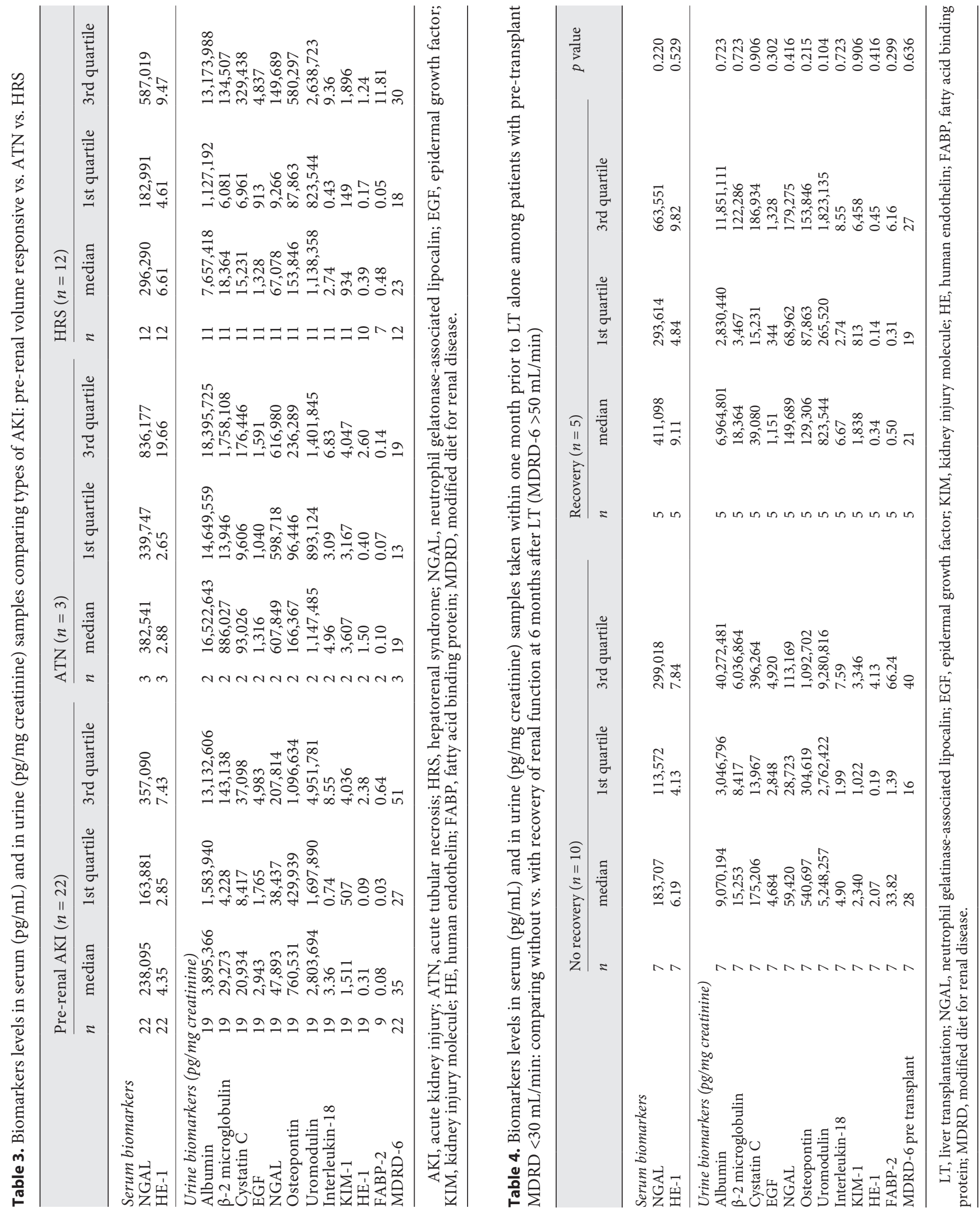
there were no differences on urinary albumin levels based on the degree of GFR decline and for AKI.

None of the biomarkers was associated with renal recovery after LT, except for UMOD. In an earlier study, a combined model including elevated OPN and tissue inhibitor of metalloproteinase- 1 , age $<57$ years, and the absence of diabetes was $82 \%$ accurate in predicting renal recovery after LT, and this combined model was more accurate compared to models including only biomarkers levels or only clinical variables [46].

Physicians in clinical practice should be extra careful in using diuretics and in counseling patients on measures for preventing AKI. This becomes more relevant in the background of shortage of donor kidneys and lack of evidence-based guidelines for the allocation of SLK transplantation [20,47]. Whether transjugular intrahepatic portosystemic shunt would be a feasible preventive strategy among cirrhosis patients who have had an episode of AKI remains a testable hypothesis [48].

Analysis of a large homogeneous prospective cohort of cirrhosis patients listed for LT, robust clinical and biomarker data, and the use of updated definition of AKI with removal of upper ceiling of $1.5 \mathrm{mg} / \mathrm{dL}$ for serum creatinine are strengths of our study. However, our study has certain limitations including data from a single center, possibility of missing some of the AKI episodes in this retrospective cohort, lack of information on the intravenous albumin use, which can confound the MDRD-6 values, and adjudicating cause of AKI based on clinical and laboratory data. Further, information on intra-operative and post-transplant variables, which could affect renal function at 6 months after LT was lacking.

In conclusion, AKI occurs frequently among patients with cirrhosis listed for LT. The development of AKI is associated with increased waitlist mortality and increased use of hospital resources. Patients with AKI who survive without a need for transplantation have about $60 \%$ prob- ability of developing a second episode of AKI within a year from the first episode of AKI. None of the pre-transplant biomarkers was associated with the recovery of renal function after LT.

We suggest developing larger multicenter studies as a basis for deriving an accurate model combining clinical variables with various biomarkers to predict the recovery of renal function after LT alone. Given encouraging data on the ability of UMOD in predicting renal recovery after LT, studies are suggested to examine proteomics and metabolomics approach on urine samples to explore other biomarkers, which could be useful in accurate differentiation of HRS from ATN and in predicting the recovery of renal function after LT.

\section{Acknowledgments}

We greatly acknowledge the support from the O'Brien Center of $\mathrm{AKI}$ at the $\mathrm{UAB}$ for conducting this study and coordinating with the laboratory measurements of biomarkers. Satish Rao gratefully acknowledges the assistance provided for this work by the NIH NIDDK UAB/UCSD O'Brien Core Center for AKI Research Grant (NIH 1P30 DK 079337). We would also like to acknowledge the support received for our work by way of grant UL1TR001417 from the National Center for Advancing Translational Sciences of the National Institute of Health.

\section{Ethics Statement}

This study was approved by the University of Alabama at Birmingham Institutional Review Board. All the participants provided blood and urine samples after written informed consent

\section{Disclosure Statement}

None of the authors have any financial or any other conflicts of interest to disclose.

\section{References}

1 Angeli P, Rodriguez E, Piano S, Ariza X, Morando F, Sola E, Romano A, Garcia E, Pavesi M, Risso A, Gerbes A, Willars C, Bernardi M, Arroyo V, Gines P; CANONIC Study Investigators of EASL-CLIF Consortium: Acute kidney injury and acute-on-chronic liver failure classifications in prognosis assessment of patients with acute decompensation of cirrhosis. Gut 2015;64:1616-1622.

2 Montoliu S, Balleste B, Planas R, Alvarez MA, Rivera M, Miquel M, Masnou H, Cirera I, Mo- rillas RM, Coll S, Sala M, Garcia-Retortillo M, Canete N, Sola R: Incidence and prognosis of different types of functional renal failure in cirrhotic patients with ascites. Clin Gastroenterol Hepatol 2010;8:616-622; quiz e80.

3 Prakash J, Mahapatra AK, Ghosh B, Arora P, Jain AK: Clinical spectrum of renal disorders in patients with cirrhosis of liver. Ren Fail 2011;33:40-46.

4 Piano S, Rosi S, Maresio G, Fasolato S, Cavallin M, Romano A, Morando F, Gola E, Frigo
AC, Gatta A, Angeli P: Evaluation of the Acute Kidney Injury Network criteria in hospitalized patients with cirrhosis and ascites. J Hepatol 2013;59:482-489.

5 Fagundes C, Barreto R, Guevara M, Garcia E, Sola E, Rodriguez E, Graupera I, Ariza X, Pereira G, Alfaro I, Cardenas A, Fernandez J, Poch E, Gines P: A modified acute kidney injury classification for diagnosis and risk stratification of impairment of kidney function in cirrhosis. J Hepatol 2013;59:474-481. 
6 Wong F, O’Leary JG, Reddy KR, Patton H, Kamath PS, Fallon MB, Garcia-Tsao G, Subramanian RM, Malik R, Maliakkal B, Thacker LR, Bajaj JS; North American Consortium for Study of End-Stage Liver Disease: New consensus definition of acute kidney injury accurately predicts 30 -day mortality in patients with cirrhosis and infection. Gastroenterology 2013;145:1280-1288.e1.

7 Gines P, Schrier RW: Renal failure in cirrhosis. N Engl J Med 2009;361:1279-1290.

8 Russ KB, Stevens TM, Singal AK: Acute kidney injury in patients with cirrhosis. J Clin Transl Hepatol 2015;3:195-204.

9 Bucsics T, Mandorfer M, Schwabl P, Bota S, Sieghart W, Ferlitsch A, Trauner M, Peck-Radosavljevic M, Reiberger T: Impact of acute kidney injury on prognosis of patients with liver cirrhosis and ascites: a retrospective cohort study. J Gastroenterol Hepatol 2015;30: 1657-1665.

10 Belcher JM, Garcia-Tsao G, Sanyal AJ, Bhogal H, Lim JK, Ansari N, Coca SG, Parikh CR; TRIBE-AKI Consortium: Association of AKI with mortality and complications in hospitalized patients with cirrhosis. Hepatology 2013; 57:753-762.

11 du Cheyron D, Bouchet B, Parienti JJ, Ramakers $\mathrm{M}$, Charbonneau P: The attributable mortality of acute renal failure in critically ill patients with liver cirrhosis. Intensive Care Med 2005;31:1693-1699.

12 Cholongitas E, Calvaruso V, Senzolo M, Patch D, Shaw S, O'Beirne J, Burroughs AK: RIFLE classification as predictive factor of mortality in patients with cirrhosis admitted to intensive care unit. J Gastroenterol Hepatol 2009; 24:1639-1647.

13 Bellomo R, Kellum JA, Ronco C: Acute kidney injury. Lancet 2012;380:756-766.

14 Schrier RW, Shchekochikhin D, Gines P: Renal failure in cirrhosis: prerenal azotemia, hepatorenal syndrome and acute tubular necrosis. Nephrol Dial Transplant 2012;27: 2625-2628.

15 Garcia-Tsao G, Parikh CR, Viola A: Acute kidney injury in cirrhosis. Hepatology 2008; 48:2064-2077.

16 Tanriover B, Mejia A, Weinstein J, Foster SV, Ghalib R, Mubarak A, Cheng SS: Analysis of kidney function and biopsy results in liver failure patients with renal dysfunction: a new look to combined liver kidney allocation in the post-MELD Era. Transplantation 2008; 86:1548-1553.

17 Charlton MR, Wall WJ, Ojo AO, Gines P, Textor S, Shihab FS, Marotta P, Cantarovich M, Eason JD, Wiesner RH, Ramsay MA, Garcia-Valdecasas JC, Neuberger JM, Feng S, Davis CL, Gonwa TA; International Liver Transplantation Society Expert Panel: Report of the first international liver transplantation society expert panel consensus conference on renal insufficiency in liver transplantation. Liver Transpl 2009;15:S1-S34.

18 Eason JD, Gonwa TA, Davis CL, Sung RS, Gerber D, Bloom RD: Proceedings of consen- sus conference on simultaneous liver kidney transplantation (SLK). Am J Transplant 2008; 8:2243-2251.

19 Kamath PS, Wiesner RH, Malinchoc M, Kremers W, Therneau TM, Kosberg CL, D'Amico G, Dickson ER, Kim WR: A model to predict survival in patients with end-stage liver disease. Hepatology 2001;33:464-470.

20 Singal AK, Salameh H, Kuo YF, Wiesner RH: Evolving frequency and outcomes of simultaneous liver kidney transplants based on liver disease etiology. Transplantation 2014;98: 216-221.

21 Schold JD, Meier-Kriesche HU, Duncan RP, Reed AI: Deceased donor kidney and liver transplantation to nonresident aliens in the United States. Transplantation 2007;84: 1548-1556.

22 Siew ED, Ware LB, Ikizler TA: Biological markers of acute kidney injury. J Am Soc Nephrol 2011;22:810-820.

23 Belcher JM, Garcia-Tsao G, Sanyal AJ, Thiessen-Philbrook H, Peixoto AJ, Perazella MA, Ansari N, Lim J, Coca SG, Parikh CR; TRIBE-AKI Consortium: Urinary biomarkers and progression of $\mathrm{AKI}$ in patients with cirrhosis. Clin J Am Soc Nephrol 2014;9: 1857-1867.

24 Wu CC, Yeung LK, Tsai WS, Tseng CF, Chu P, Huang TY, Lin YF, Lu KC: Incidence and factors predictive of acute renal failure in patients with advanced liver cirrhosis. Clin Nephrol 2006;65:28-33.

25 Tandon P, James MT, Abraldes JG, Karvellas CJ, Ye F, Pannu N: Relevance of new definitions to incidence and prognosis of acute kidney injury in hospitalized patients with cirrhosis: a retrospective population-based cohort study. PLoS One 2016;11:e0160394.

26 Nickolas TL, O’Rourke MJ, Yang J, Sise ME, Canetta PA, Barasch N, Buchen C, Khan F, Mori K, Giglio J, Devarajan P, Barasch J: Sensitivity and specificity of a single emergency department measurement of urinary neutrophil gelatinase-associated lipocalin for diagnosing acute kidney injury. Ann Intern Med 2008;148:810-819.

27 Mishra J, Dent C, Tarabishi R, Mitsnefes MM, Ma Q, Kelly C, Ruff SM, Zahedi K, Shao M, Bean J, Mori K, Barasch J, Devarajan P: Neutrophil gelatinase-associated lipocalin (NGAL) as a biomarker for acute renal injury after cardiac surgery. Lancet 2005;365:1231-1238.

28 Han WK, Bailly V, Abichandani R, Thadhani R, Bonventre JV: Kidney Injury Molecule-1 (KIM-1): a novel biomarker for human renal proximal tubule injury. Kidney Int 2002;62: 237-244.

29 Liu X, Li NS, Lv LS, Huang JH, Tang H, Chen JX, Ma HJ, Wu XM, Lou TQ: A comparison of the performances of an artificial neural network and a regression model for GFR estimation. Am J Kidney Dis 2013;62:1109-1115.

30 Yokoyama T, Kamijo-Ikemori A, Sugaya T, Hoshino S, Yasuda T, Kimura K: Urinary excretion of liver type fatty acid binding protein accurately reflects the degree of tubulointer- stitial damage. Am J Pathol 2009;174:20962106

31 Francoz C, Nadim MK, Durand F: Kidney biomarkers in cirrhosis. J Hepatol 2016;65: 809-824.

32 Fagundes C, Pepin MN, Guevara M, Barreto R, Casals G, Sola E, Pereira G, Rodriguez E, Garcia E, Prado V, Poch E, Jimenez W, Fernandez J, Arroyo V, Gines P: Urinary neutrophil gelatinase-associated lipocalin as biomarker in the differential diagnosis of impairment of kidney function in cirrhosis. J Hepatol 2012;57:267-273.

33 Xu Y, Xie Y, Shao X, Ni Z, Mou S: L-FABP: A novel biomarker of kidney disease. Clin Chim Acta 2015;445:85-90.

34 Chen YW, Wu CJ, Chang CW, Lee SY, Sun FJ, Chen HH: Renal function in patients with liver cirrhosis. Nephron Clin Pract 2011;118: c195-c203.

35 Tsien CD, Rabie R, Wong F: Acute kidney injury in decompensated cirrhosis. Gut 2013; 62:131-137.

36 Belcher JM, Sanyal AJ, Peixoto AJ, Perazella MA, Lim J, Thiessen-Philbrook H, Ansari N, Coca SG, Garcia-Tsao G, Parikh CR; TRIBEAKI Consortium: Kidney biomarkers and differential diagnosis of patients with cirrhosis and acute kidney injury. Hepatology 2014;60: 622-632.

37 Ariza X, Sola E, Elia C, Barreto R, Moreira R, Morales-Ruiz M, Graupera I, Rodriguez E, Huelin P, Sole C, Fernandez J, Jimenez W, Arroyo V, Gines P: Analysis of a urinary biomarker panel for clinical outcomes assessment in cirrhosis. PLoS One 2015; 10: e0128145.

38 Yanagisawa M, Kurihara H, Kimura S, Tomobe Y, Kobayashi M, Mitsui Y, Yazaki Y, Goto K, Masaki T: A novel potent vasoconstrictor peptide produced by vascular endothelial cells. Nature 1988;332:411-415.

39 Moore K, Wendon J, Frazer M, Karani J, Williams R, Badr K: Plasma endothelin immunoreactivity in liver disease and the hepatorenal syndrome. N Engl J Med 1992;327:1774-1778.

40 Mindikoglu AL, Dowling TC, Weir MR, Seliger SL, Christenson RH, Magder LS: Performance of chronic kidney disease epidemiology collaboration creatinine-cystatin C equation for estimating kidney function in cirrhosis. Hepatology 2014;59:1532-1542.

41 Nejat M, Pickering JW, Walker RJ, Endre ZH: Rapid detection of acute kidney injury by plasma cystatin $\mathrm{C}$ in the intensive care unit. Nephrol Dial Transplant 2010;25:3283-3289.

42 Bianchi C, Donadio C, Tramonti G, Consan C, Lorusso P, Bonino C, Lunghi F: Uninephrectomy increases kidney beta2-microglobulin: can it play a role in the progression of kidney damage? Ren Fail 2001;23:507-516.

43 Shinkai S, Chaves PH, Fujiwara Y, Watanabe S, Shibata H, Yoshida H, Suzuki T: Beta2-microglobulin for risk stratification of total mortality in the elderly population: comparison with cystatin $\mathrm{C}$ and C-reactive protein. Arch Intern Med 2008;168:200-206. 
44 Nejat M, Pickering JW, Walker RJ, Westhuyzen J, Shaw GM, Frampton CM, Endre ZH: Urinary cystatin $\mathrm{C}$ is diagnostic of acute kidney injury and sepsis, and predicts mortality in the intensive care unit. Crit Care 2010;14:R85.

45 Al-Malki AL: Assessment of urinary osteopontin in association with podocyte for early predication of nephropathy in diabetic patients. Dis Markers 2014;2014:493736.
46 Levitsky J, Baker TB, Jie C, Ahya S, Levin M, Friedewald J, Al-Saden P, Salomon DR, Abecassis MM: Plasma protein biomarkers enhance the clinical prediction of kidney injury recovery in patients undergoing liver transplantation. Hepatology 2014;60:20172026.

47 Formica RN, Aeder M, Boyle G, Kucheryavaya $A$, Stewart $D$, Hirose R, Mulligan D: Si- multaneous liver-kidney allocation policy: a proposal to optimize appropriate utilization of scarce resources. Am J Transplant 2016;16: 758-766.

48 Bai M, Qi XS, Yang ZP, Yang M, Fan DM, Han GH: TIPS improves liver transplantation-free survival in cirrhotic patients with refractory ascites: an updated meta-analysis. World J Gastroenterol 2014;20:2704-2714. 